\title{
In situ retrocaval skeletonized right internal thoracic artery anastomosed to the circumflex system via transverse sinus: Technical aspects and postoperative outcome
}

Massimo Bonacchi, MD ${ }^{\mathrm{a}}$

Edvin Prifti, MD, PhD

Francesco Battaglia, MD

Giacomo Frati, MDa

Guido Sani, MDa

Georges Popoff, MD
From the Department of Cardiac Surgery, ${ }^{a}$ University of Florence, Firenze, Italy, and Villa Maria Beatrice Hospital, ${ }^{\text {b }}$ Firenze, Italy.

Received for publication July 18 , 2002; revisions requested Sept 5, 2002; revisions received June 3, 2003; accepted for publication June 5, 2003.

Address for reprints: Massimo Bonacchi, MD, Cattedra di Cardiochirurgia, University Hospital of Florence "Careggi," Viale Morgagni, 85, 50134 Firenze, Italy (E-mail: mbonacchi@unifi.it).

J Thorac Cardiovasc Surg 2003;126: $1302-13$

Copyright () 2003 by The American Association for Thoracic Surgery

$0022-5223 / 2003 \$ 30.00+0$

doi:10.1016/S0022-5223(03)01277-7
Background: The aim of this study was to investigate whether, by using the in situ right internal thoracic artery via the transverse sinus (eventually retrocaval), both the proximal and distal major branches of the circumflex system could be grafted and to evaluate the early and late outcome in these patients.

Methods: Between January 1997 and March 2002, 452 consecutive patients underwent grafting of the circumflex system with the in situ skeletonized right internal thoracic artery routed via the transverse sinus. The mean age was $62.4 \pm 10.3$ years. A mean of $2.2 \pm 0.3$ arterial grafts per patient were used, and $271(60 \%)$ patients underwent total arterial myocardial revascularization. At 3 months after surgery, 86 patients (right $\mathrm{Y}$ or $\mathrm{T}$ graft) underwent echo color Doppler imaging before and after an adenosine provocative test. The mean follow-up was $27 \pm 8$ months.

Results: The success rate of skeletonized right internal thoracic artery grafting to the circumflex system branch was $100 \%$. There were 15 (3.4\%) hospital deaths. In 116 patients who underwent postoperative angiography, the total patency rates of the right and left internal thoracic arteries were $94 \%$ and $96.6 \%$, respectively. Strong predictors for nonfunctional internal thoracic artery grafts were a small internal thoracic artery caliber $(P<.001)$, recipient coronary artery diameter less than 1.5 $\mathrm{mm}(P=.012)$, stenotic lesions of less than $60 \%(P=.016)$, and diffuse stenotic lesions $(P=.015)$ of the recipient coronary artery. In 86 patients who underwent postoperative echo color Doppler imaging, the flow reserves at the main stem of the left and right internal thoracic arteries were $2.24 \pm 0.5$ and $2.48 \pm 0.6$, respectively. Cumulative actuarial survival at 3 years was $96.3 \%$, and event-free cumulative survival was $93 \%$. The Cox model revealed a left ventricular ejection fraction of less than $35 \%(P=.016)$, age greater than 70 years $(P=.025)$, New York Heart Association grade greater than III $(P=.0019)$, nontotal arterial myocardial revascularization $(P=.002)$, and the preoperative presence of more than 1 ischemic area $(P<.001)$ as strong predictors for poor overall cumulative event-free survival.

Conclusions: The skeletonized right internal thoracic artery, placed via the transverse sinus and eventually retrocaval, can reach most branches of the circumflex system and is associated with an excellent patency rate. The predictors for poor overall event-free survival seem to be similar to those of the general population undergoing conventional coronary artery bypass grafting. Use of bilateral internal thoracic arteries and in situ right internal thoracic artery grafting via the transverse sinus offers the possibility of various configuration constructions, making possible total arterial myocardial revascularization with a minimum number of arterial conduits. 
I mproved survival and reduced late cardiac events have been documented in patients who receive a left internal thoracic artery (LITA) grafted to the left anterior descending artery (LAD) compared with patients revascularized with saphenous veins. ${ }^{1}$ To enhance such results, other arterial conduits, particularly the right internal thoracic artery (RITA), have been used with excellent late outcome. ${ }^{2}$ However, the optimal RITA configuration is not yet established. Tatoulis and colleagues ${ }^{3}$ reported that the distal obtuse marginal artery could not be readily reached with in situ RITA (s-RITA) grafting. Some have advocated free RITA (fRITA) to overcome the anatomic limitations of the s-RITA, ${ }^{3}$ and others anastomose the s-RITA to the LAD. ${ }^{4,5}$ Anatomic studies using cadavers have indeed shown that any coronary artery can be reached with the s-RITA. ${ }^{6}$ Other reports have shown satisfactory early results with revascularizing the s-RITA to the proximal branches of the circumflex system via the transverse sinus. ${ }^{7-11}$ Moreover, there are still controversies regarding the fact that pulling the RITA through the transverse sinus could compromise both its patency and flow capacity. ${ }^{12}$ Since 1997 , we have used different new configurations for total arterial myocardial revascularization (TAMR) by using the s-RITA routed via the transverse sinus and eventually behind the superior caval vein. $^{13-15}$

The aims of this study were (1) to investigate whether, by using the s-RITA via the transverse sinus and eventually retrocavally, both the proximal and distal major branches of the circumflex system could be reached and grafted and (2) to evaluate the early and late outcome in this group of patients in terms of mortality, morbidity, and internal thoracic artery (ITA) patency.

\section{Patients and Methods}

Between January 1997 and March 2002, 452 consecutive patients underwent grafting of the circumflex system with a skeletonized $\mathrm{s}$-RITA routed via the transverse sinus. The inclusion criteria were the presence of an angiographically graftable branch of the circumflex system and bilateral skeletonized ITA use. Diabetes, female sex, old age, and chronic obstructive pulmonary disease were not considered contraindications for bilateral ITA use.

\section{Patient Characteristics}

The preoperative patient characteristics are summarized in Table 1. The posterolateral branch of the circumflex system and the obtuse marginal branch during coronary arteriography were defined on the basis of the American Heart Association reporting system for patients with coronary artery disease. ${ }^{16}$ The size of the perfusion areas of the recipient coronary artery was qualitatively graded as large, medium, small, or tiny (score, 1-4). Graftable branches were defined as those with an area of 1 to 3 . The primary target branch of the circumflex system for s-RITA grafting was selected before surgery as follows: in patients with 2 graftable branches, the branch with the larger perfusion area was selected as a primary
TABLE 1. Demographic and clinical characteristics

\begin{tabular}{lc}
\hline Variable & Data \\
\hline Total no. patients & 452 \\
Women & $109(24 \%)$ \\
Age, y (mean \pm SD) & $62.4 \pm 10.3$ \\
Age, y (range) & $38-77$ \\
Diabetes & $103(22.8 \%)$ \\
Hypertension & $273(60.4 \%)$ \\
Smoking & $314(75 \%)$ \\
Dyslipidemia & $167(37 \%)$ \\
Hypercholesterolemia & $31(6.9 \%)$ \\
Chronic renal failure/creatinine level $>1.5$ mg/dL & $21(4.7 \%)$ \\
Cerebral ischemia & $12(2.7 \%)$ \\
Peripheral vascular disease & $27(6 \%)$ \\
Chronic obstructive pulmonary disease & $42(9.3 \%)$ \\
New York Heart Association functional class & $1.5 \pm 0.8$ \\
Canadian Cardiovascular Society class & $3.3 \pm 0.7$ \\
Stable angina & $224(49.6 \%)$ \\
Unstable angina & $198(43.8 \%)$ \\
Silent angina & $30(6.6 \%)$ \\
Prior myocardial infarction & $208(46 \%)$ \\
Prior coronary angioplasty & $96(21.2 \%)$ \\
Heavily calcified aorta & $27(6 \%)$ \\
Previous saphenectomy or varicose saphenous & $31(6.9 \%)$ \\
$\quad$ veins & \\
Coronary angiography data & \\
Three-vessel disease & $288(63.7 \%)$ \\
Two-vessel disease & $164(36.3 \%)$ \\
Left main coronary artery stenosis & $117(26 \%)$ \\
Left ventricular ejection fraction <35\% & $96(21.2 \%)$ \\
New York Heart Association class $>$ III & $89(19.7 \%)$ \\
Mean left ventricular ejection fraction (\%) & $50.6 \pm 11$ \\
\hline Data & \\
\hline &
\end{tabular}

Data are mean $\pm \mathrm{SD}$ or $\mathrm{n}(\%)$ unless otherwise noted.

target; if both branches had identical perfusion areas, the distal branch (posterolateral branch of the circumflex artery) was selected as the primary target for s-RITA grafting, and the other vessel was revascularized with other available conduits, if indicated.

\section{Arterial Conduit Preparation}

After a median longitudinal sternotomy, the LITA and RITA were harvested in a skeletonized fashion as previously described, ${ }^{13-15}$ extending 1.5 to $2 \mathrm{~cm}$ below the bifurcation and without opening the pleural cavities. In 3 cases, the phrenic nerve was closed to the RITA origin; postoperative diaphragmatic paralysis developed in these patients, probably due to electricity conduction, which reversed completely within 1 month. In both sides of the superior mediastinum, the pleurae and pericardial tissues were dissected, and the ITA "beds" were created. The bed of the ITAs allows the ITAs to lie medially and posteriorly. The lung and ventilation do not produce any stretch or distortion of the arteries, and at the same time, the ITAs are protected should re-sternotomy be required. Then the s-RITA was routed retrocavally (in 264 patients), usually superiorly to the azygos vein, which was not divided. The inside blood pressure forces the graft to have the right orientation and to avoid distortion. The size of the ITAs (only ITAs $>1.5 \mathrm{~mm}$ were used) was measured at the anastomotic site before anastomosis 


\section{TABLE 2. Operative data}

\begin{tabular}{lc}
\hline Variable & Data \\
\hline Cardiopulmonary bypass time (min) & $98 \pm 16$ \\
Aortic crossclamping time (min) & $69 \pm 8.4$ \\
Off-pump coronary artery bypass grafting & $68(15 \%)$ \\
RITA grafted to the OM & $43(63.2 \%)$ \\
RITA grafted to the PL & $25(36.8 \%)$ \\
No. of distal anastomoses & $3.1 \pm 0.5$ \\
Coronary endarterectomy & $32(7.1 \%)$ \\
Sequential anastomoses & $25(5.5 \%)$ \\
LITA & $452(100 \%)$ \\
RITA & $452(100 \%)$ \\
Grafted to the OM & $262(58 \%)$ \\
Grafted to the PL & $190(42 \%)$ \\
RITA grafted to the PL when both Cfx & $23(12 \%)$ \\
$\quad$ branches had almost identical & \\
perfusion areas & \\
Retrocaval RITA routing & $264(58.4 \%)$ \\
Radial artery used & $91(20 \%)$ \\
Arterial grafts/patient & $2.2 \pm 0.3$ \\
Total arterial myocardial revascularization & $271(60 \%)$ \\
Composite grafts & \\
Right Y graft & $71(15.7 \%)$ \\
Left Y graft & $113(25 \%)$ \\
Right T graft & $15(3.3 \%)$ \\
Inverted T graft & $3(0.7 \%)$ \\
Composite anastomosis ( $\omega$-anastomosis) & $16(3.5 \%)$ \\
Associated surgical procedures & \\
Aortic valve replacement & $21(4.6 \%)$ \\
Mitral valve repair & $18(4 \%)$ \\
Mitral valve replacement & $13(2.9 \%)$ \\
Carotid artery endarterectomy & $19(2 \%)$ \\
Cholecystectomy & $4(0.9 \%)$ \\
Postoperative surgical procedures & $5(1.1 \%)$ \\
Revision for deep sternal wound infection & $13(3 \%)$ \\
Surgical revision for bleeding & \\
\hline Data & \\
\hline
\end{tabular}

Data are $\mathrm{n}(\%)$ or mean $\pm \mathrm{SD}$. OM, Obtuse marginal artery; $C f x$, circumflex artery; RITA, right internal thoracic artery; LITA, left internal thoracic artery; $P L$, posterolateral branch of the circumflex artery.

was performed. The free flow of the ITAs was evaluated during surgery in all cases. Only ITAs with a free flow greater than 50 $\mathrm{mL} / \mathrm{min}$ were used. After heparin administration, the ITAs were cut, and the distal ends were closed with a hemoclip and covered with gauze saturated with warm $\left(37^{\circ} \mathrm{C}-40^{\circ} \mathrm{C}\right)$ papaverine solution $(4 \mathrm{mg} / \mathrm{mL})$.The radial artery was harvested simultaneously with preparation of the ITAs at the nondominant arm. Preoperative assessment of the palmar arch was performed with an Allen test or with digital plethysmography. The radial artery was cut and cannulated with a 1-mm elastic needle through which $10 \mathrm{~mL}$ of warm Ringer's lactate solution containing diltiazem $(5 \mathrm{mg} / \mathrm{mL})$ and nitroprusside $(10 \mathrm{mg} / \mathrm{mL})$ was gently injected.

\section{Surgical Techniques}

Normothermia and intermittent anterograde/retrograde cold blood cardioplegia were used. On pump and with a beating heart, the coronary arteries were explored, and possible anastomosis locations were determined. A total of 105 patients underwent myocardial revascularization according to the previously described tech- niques. ${ }^{13-15}$ The in situ LITA (s-LITA) was anastomosed to the LAD in all patients. The s-RITA was anastomosed to the most important branch of the circumflex system by lifting and rotating the left ventricle (LV) to the right side to expose its lateral wall. Sewing the s-RITA in this position is easier but requires additional length. The s-RITA may sometimes be tight during this part of the operation; however, the release of the heart after the anastomosis completion restores adequate length and looseness of the graft tension because of heart rotation. The size of the recipient coronary artery was measured by passing a metal probe through it (1-2.5 $\mathrm{mm})$. In 68 patients who underwent off-pump coronary artery bypass grafting (CABG), exposure of the coronary arteries was achieved with pericardial traction sutures, and immobilization was maintained by an Octopus 1 or 2 (Medtronic, Inc, Minneapolis, Minn) stabilizer. The intracoronary shunts were rarely used. The intraoperative data are given in Table 2 . The intravenous nitroderivatives therapy was initiated immediately after the aorta was unclamped, according to the hemodynamic situation. It was continued during the postoperative course in the intensive care unit and eventually combined with diltiazem. The oral vasodilator therapy was continued for almost 4 weeks after surgery.

\section{Postoperative Graft Evaluation and Follow-up}

At 3 months after surgery, 86 patients (right $\mathrm{Y}$ or $\mathrm{T}$ graft) underwent transthoracic contrast-enhanced color Doppler echocardiography (Levovist; Schering AG, Berlin, Germany) before and after the adenosine provocative test. ${ }^{13-15}$ The probe $(7.5 \mathrm{MHz})$ was positioned at the left and right first and second intercostal spaces or the supraclavicular fossa for proximal ITA visualization and at the third and fourth intercostal spaces for mid-distal LITA visualization. The ITA's diameter, peak systolic velocity, peak diastolic velocity, mean flow, and graft flow reserve were measured. These data were registered at rest and at 1 minute after adenosine administration $\left(140 \mu \mathrm{g} \cdot \mathrm{kg}^{-1} \cdot \min ^{-1}\right.$ for 3 minutes). Initially we performed postoperative angiography in all patients who underwent RITA anastomosed to the circumflex system through the transverse sinus. Later, only patients with doubtful postoperative results shown by echo-dobutamine, scintigraphy, or both underwent coronary angiography. A total of 116 patients underwent postoperative angiographic examination.

\section{Definitions}

Hospital mortality was defined as death for any reason occurring within 30 days after surgery. Perioperative myocardial infarction was defined as the appearance of new $\mathrm{Q}$ waves, significant loss of $\mathrm{R}$-wave forces, and a peak creatine kinase MB (CK-MB) greater than $10 \%$. Low cardiac output syndrome was defined as a cardiac index $<2.0 \mathrm{~L} \cdot \mathrm{min}^{-1} \cdot \mathrm{m}^{-2}$ necessitating pharmacologic support, intra-aortic balloon pump (IABP) insertion, or both. String sign was defined as a diffuse narrowing of distal ITAs. Only grafts of good caliber, with no occlusion, string sign, or significant stenosis, were considered patent.

\section{Statistical Analysis}

Group statistics were expressed as mean \pm SD. The generalized Wilcoxon test was performed for statistical analysis between groups. The Fisher exact test was used for noncontinuous variables. The relationship between preoperative and postoperative 
variables within the same group was assessed by the McNemar test. The multivariate logistic regression model was used to determine the predictors for poor early survival. Multivariate Cox proportional regression was performed to determine independent predictors. The cumulative risk-adjusted mortality was constructed on the basis of the EuroSCORE model. Long-term survival was calculated with the Kaplan-Meier method and the log-rank test.

\section{Results}

In all cases, it was possible to anastomose the skeletonized s-RITA to the primary vessel target of the circumflex artery, as planned before surgery. There were 15 (3.4\%) hospital deaths (Table 3). The multivariate analysis revealed an LV ejection fraction $(\mathrm{LVEF})<35 \%$, age $>70$ years, and 1 or more irreversible ischemic areas as strong predictors for poor early postoperative outcome (Table 4). In another multivariate model, the predictors for early death and major postoperative adverse outcome were LVEF $<35 \%(P=$ $.0044)$, cardiopulmonary bypass time $(P=.017), 1$ or more irreversible ischemic areas $(P=.0087)$, age $>70$ years $(P$ $=.016)$, and associated surgical procedures $(P=.032)$.

In 308 patients with LVEF greater than $35 \%$ undergoing CABG alone, the hospital mortality was $1.3 \%$ (4 patients; Table 3$)$. IABP insertion was required in $8(1.8 \%)$ patients: 3 had a preoperative LVEF greater than $30 \%$, and the IABPs were used before surgery. Perioperative myocardial infarction occurred in $10(2.2 \%)$ patients; in 5 patients, this was correlated with a vein graft anastomosed to a very diseased posterior interventricular artery. There were $13(3 \%)$ reexplorations for bleeding, but none was related to RITA. After surgery, 12 patients $(2.6 \%)$ had a deep sternal wound infection or skin layer dehiscence. Only 5 of them had diabetes $(P=.26)$.

To clarify the characteristics of s-RITA grafting in 116 patients who underwent postoperative angiography at a mean of $17 \pm 5.6$ months, the intraoperative data between the RITA and LITA were compared (Table 5). As shown, the length of the s-RITA to graft 1 of the circumflex branches was longer than the s-LITA, demonstrating that the distal, smaller, and muscular segment of s-RITA was used. In addition, the RITA's recipient coronary artery caliber and perfusion were significantly smaller than those of the LAD. The study was inadequate to evaluate the s-RITA in 2 patients, so they were excluded from the angiographic analysis. Two RITAs anastomosed to the obtuse marginal branch were occluded: the occlusion was located at the anastomotic site. A string-like phenomenon was identified in 3 RITAs and 1 LITA. Two other RITAs and 3 LITAs had significant stenotic lesions. The total patency rates for the s-RITA and s-LITA were $94 \%$ and $96.6 \%$, respectively. We considered nonfunctioning grafts presenting a string sign phenomenon as nonpatent grafts; however, these grafts may recruit their flow capacity the recipient coronary artery becomes increasingly stenotic. ${ }^{17}$
TABLE 3. Postoperative survival and morbidity

\begin{tabular}{lc}
\hline Variables & Data \\
\hline Intensive care unit stay (d) & $1.1 \pm 0.6$ \\
Mechanical ventilation (h) & $6.7 \pm 2.4$ \\
Prolonged ventilation & $10(2.2 \%)$ \\
Postoperative intra-aortic balloon pump use & $8(1.8 \%)$ \\
Perioperative myocardial infarction & $10(2.2 \%)$ \\
Inotrope use (dopamine $>6 \mu \mathrm{g} \cdot \mathrm{kg}^{-1} \cdot \mathrm{min}^{-1}$ ) & $31(6.9 \%)$ \\
Atrial fibrillation & $46(10 \%)$ \\
Other arrhythmias & $15(3.3 \%)$ \\
Bleeding >1000 mL & $40(8.8 \%)$ \\
Renal dysfunction & $26(5.8 \%)^{*}$ \\
Postoperative ultrafiltration/hemodialysis & $8(1.8 \%)$ \\
Unilateral pleural effusions (chest radiograph) & $32(7 \%)$ \\
Bilateral pleural effusions (chest radiograph) & $21(4.7 \%)$ \\
Postoperative thoracocentesis & $36(8 \%)$ \\
Atelectasis during intensive care unit stay & $48(11 \%)$ \\
Pneumothorax & $21(5.6 \%)$ \\
Diaphragm impairment & $3(0.4 \%)$ \\
Bronchopneumonia & $14(3.1 \%)$ \\
Gastrointestinal complications & $10(2.2 \%)$ \\
Transient neurologic complications & $10(2.2 \%)$ \\
Stroke & $2(0.44 \%) \dagger$ \\
Multiorgan failure & $3(0.04 \%)$ \\
Sepsis & $5(1.1 \%)$ \\
Skin layer dehiscence & $7(1.5 \%)$ \\
Deep sternal wound infection & $5(1.1 \%)$ \\
Hospital mortality & $15(3.3 \%)$ \\
Causes of hospital mortality & \\
Acute myocardial infarction & $4(26.7 \%)$ \\
Aortic dissection & $1(6.7 \%)$ \\
Low cardiac output & $5(33 \%)$ \\
Multiorgan failure & $2(13.3 \%)$ \\
Sepsis & $1(6.7 \%)$ \\
Stroke & $1(6.7 \%)$ \\
Bleeding & $1(6.7 \%)$ \\
Data &
\end{tabular}

Data are $\mathrm{n}(\%)$ or mean $\pm \mathrm{SD}$.

*The $1 \mathrm{mg} / \mathrm{dL}$ increment of the postoperative creatinine level compared with the preoperative value was defined as postoperative renal dysfunction.

tOne postoperative stroke was identified in 1 patient who underwent concomitant carotid endarterectomy and the other in a patient who underwent associated mitral valve surgery.

There were no significant differences in patency rates between s-LITA and s-RITA grafts. Strong predictors for nonfunctional ITA grafts were diameter of the recipient coronary artery less than $1.5 \mathrm{~mm}(P=.012)$, small ITA caliber $(P=.00018)$, stenosis less than $60 \%$ of the recipient coronary artery $(P=.016)$, and diffuse stenotic lesions of the recipient coronary artery $(P=.015$; Table 5$)$.

A total of 86 patients who underwent right $\mathrm{Y}$ or $\mathrm{T}$ grafting underwent postoperative echo color Doppler examination at rest and after adenosine provocative testing within 3 months after CABG. The graft flow reserve at the RITA main stem was higher in all measurements compared with the LITA main stem $(P=.003$; Table 6$)$. The mean Flow $_{i}$ $\left(\mathrm{mL} \cdot \min ^{-1} \cdot \mathrm{m}^{-2}\right)$ at the RITA main stem was significantly 
TABLE 4. Predictors for early and overall midterm poor postoperative outcome

Predictors for poor early postoperative survival

\begin{tabular}{|c|c|c|c|c|c|c|}
\hline Variable & $\begin{array}{c}\text { Death } \\
(n=15)\end{array}$ & $\begin{array}{l}\text { Survival } \\
(n=437)\end{array}$ & & $\mathbf{O R}$ & & $P$ value \\
\hline \multicolumn{7}{|l|}{ Univariate analysis } \\
\hline Age $>70$ y & $8 / 7$ & $90 / 347$ & & 7.3 & & .007 \\
\hline LVEF $<35 \%$ & $9 / 6$ & $87 / 350$ & & 11.6 & & .001 \\
\hline NYHA class $>$ III & $9 / 6$ & $80 / 357$ & & 13.4 & & .0001 \\
\hline Associated surgical procedures & $6 / 9$ & $65 / 372$ & & 5.14 & & .023 \\
\hline No TAMR & $13 / 2$ & $168 / 269$ & & 12.1 & & .001 \\
\hline Cardiopulmonary bypass time (min) & $132 \pm 24$ & $97.4 \pm 15$ & & 8.6 & & .001 \\
\hline Aortic crossclamping time & $96 \pm 16$ & $68.6 \pm 7.8$ & & 12.7 & & .001 \\
\hline$>1 \mathrm{IIA}$ & $8 / 7$ & $29 / 408$ & & 15.4 & & .0001 \\
\hline \multicolumn{7}{|c|}{ Multivariate analysis (stepwise regression model) } \\
\hline Variable & $\beta$ SE & $\mathrm{B}$ & B SE & & $t$ & $P$ value \\
\hline$>1 \| A$ & .047 & 0.11 & 0.022 & & 4.86 & .000 \\
\hline Age $>70$ y & .075 & 0.11 & 0.035 & & 3.03 & .0026 \\
\hline LVEF $<35 \%$ & .13 & 0.14 & 0.058 & & 2.44 & .015 \\
\hline
\end{tabular}

Predictors for poor overall midterm survival (Cox model)

\begin{tabular}{|c|c|c|c|c|c|c|}
\hline Variable & $\beta$ value & SE & $t$ & $\beta$ exponent & Wald statistic & $P$ value \\
\hline \multicolumn{7}{|c|}{$\chi^{2}=32,3702 ; g d l=7 ; P=.00003$} \\
\hline LVEF $<35 \%$ & .41 & 0.17 & 2.41 & 1.51 & 5.79 & .016 \\
\hline Age $>70 y$ & -2.11 & 0.95 & -2.24 & 8.30 & 5.01 & .025 \\
\hline NYHA grade $>$ III & -2.3 & 0.74 & -3.11 & .10 & 9.64 & .0019 \\
\hline No TAMR & -.46 & 0.15 & -3.09 & .63 & 9.57 & .002 \\
\hline$>1 \| A$ & .65 & 0.16 & 3.97 & 1.91 & 15.78 & .0001 \\
\hline
\end{tabular}

LVEF, Left ventricular ejection fraction; NYHA, New York Heart Association; TAMR, total arterial myocardial revascularization; IIA, irreversible ischemic area; $O R$, odds ratio; $\chi^{2}$, rate of maximal equality; $g d l$, freedom's degrees.

higher than the flow at the LITA main stem in all measurements.

The mean follow-up was $27 \pm 8$ months (range, 1-62 months). Cumulative actuarial survival at $1,2,3$, and 4 years was $99.3 \%, 97.7 \%, 96.3 \%$, and $93.3 \%$, respectively, and event-free cumulative survival was $99.3 \%, 94.7 \%$, $93 \%$, and $90.2 \%$, respectively (Figure $1, A$ and $B$ ). The cumulative risk-adjusted survival according to the EuroSCORE model is given in Figure 1, $C$. The actuarial survival was significantly lower in patients with an LVEF less than $35 \%$ (Figure 2, $A$ ), in those who underwent combined operations (Figure 2, B), in those older than 70 years (Figure 2, C), and in those who did not undergo TAMR (Figure 2, $E)$. At follow-up, 2 patients underwent coronary angioplasty, and 2 patients had a myocardial infarction. Two other patients underwent re-CABG. These events occurred in nonrevascularized coronary arteries or because of stenosis or occlusion of the saphenous vein graft. Another patient with an LVEF less than $30 \%$, ischemic mitral valve regurgitation, and a heavily calcified aorta, who had undergone mitral valve repair simultaneously with $\mathrm{CABG}$, underwent cardiac transplantation at 2 years after the first operation. Another patient who underwent associated aortic valve replacement required reoperation because of endocarditis. The remaining 278 patients underwent stress thallium 201 scintigraphy, echo-dobutamine stress testing, or ergometric testing within 6 months after surgery. None of these patients showed signs of any residual ischemia.

Among a series of variables included in the Cox model, the statistical analysis showed that an LVEF less than 35\%, age greater than 70 years, New York Heart Association class greater than III, non-TAMR, and the preoperative presence of more than 1 ischemic area were strong predictors for poor overall cumulative event-free survival (Table $4)$.

\section{Discussion}

The use of ITAs has developed in an incremental manner from anastomosing the s-LITA to the LAD, to the use of bilateral free or/and sequential ITAs and preconstructed grafts, ${ }^{18,19}$ because of its excellent long-term patency, ${ }^{1,2,20}$ with similar patency rates between the s-RITA and s-LITA. ${ }^{7,21}$ Different ITA harvesting techniques have been used, such as the pedunculated, semiskeletonized, and skeletonized technique. Harvesting the ITAs according to the skeletonized technique results in a longer arterial conduit, larger diameter, and greater flow. ${ }^{22}$ Moreover, the skeletonized technique is associated with fewer infections, ${ }^{5}$ probably because of reduced traumatic and ischemic injuries of the mediastinal tissues. ${ }^{19}$ 
TABLE 5. Postoperative angiographic data in $\mathbf{1 1 6}$ patients and predictors for nonfunctional, stenotic, or occluded internal thoracic arteries at follow-up

\begin{tabular}{|c|c|c|c|c|c|c|}
\hline \multicolumn{2}{|l|}{ Variable } & \multicolumn{2}{|r|}{$\begin{array}{l}\text { RITA to Cfx } \\
\text { (n = 116) }\end{array}$} & \multicolumn{2}{|c|}{$\begin{array}{l}\text { LITA to LAD } \\
(\mathrm{n}=116)\end{array}$} & $P$ value \\
\hline \multicolumn{3}{|l|}{ Length of the ITA $(\mathrm{cm})$} & $19.3 \pm 2.4$ & \multicolumn{2}{|c|}{$14.1 \pm 3.7$} & .001 \\
\hline \multicolumn{7}{|l|}{ ITA caliber } \\
\hline & \multicolumn{2}{|r|}{$9(8 \%)$} & \multicolumn{2}{|c|}{$6(5 \%)$} & .59 \\
\hline \multicolumn{2}{|l|}{ Medium $(1.5-2.0 \mathrm{~cm})$} & \multicolumn{2}{|r|}{$82(71 \%)$} & \multicolumn{2}{|c|}{$76(66 \%)$} & .48 \\
\hline \multicolumn{2}{|l|}{ Large $(>2 \mathrm{~cm})$} & \multicolumn{2}{|r|}{$25(21 \%)$} & \multicolumn{2}{|c|}{$34(29 \%)$} & .23 \\
\hline \multicolumn{2}{|c|}{ Size of recipient coronary artery $>1.5 \mathrm{~mm}$} & \multicolumn{2}{|r|}{$97(83.6 \%)$} & \multicolumn{2}{|c|}{$112(96.6 \%)$} & .002 \\
\hline \multicolumn{7}{|c|}{ Perfusion area } \\
\hline \multicolumn{2}{|l|}{ Small } & \multicolumn{2}{|r|}{$20(17.3 \%)$} & \multicolumn{2}{|c|}{0} & .001 \\
\hline \multicolumn{2}{|l|}{ Medium } & \multicolumn{2}{|r|}{$88(75.9 \%)$} & \multicolumn{2}{|c|}{$15(13 \%)$} & .001 \\
\hline \multicolumn{2}{|l|}{ Large } & \multicolumn{2}{|r|}{$8(6.9 \%)$} & \multicolumn{2}{|c|}{$101(87 \%)$} & .001 \\
\hline \multicolumn{7}{|c|}{ Postoperative angiographic data } \\
\hline Occlusion & & & $2(1.7 \%)$ & & & .48 \\
\hline Stenosis & & & $2(1.7 \%)$ & & & 1.0 \\
\hline String sign & & & $3(2.6 \%)$ & & & .61 \\
\hline Nonfunctioning RITAs ana & to $\mathrm{PL}$ & & 4 & & & \\
\hline Off-pump CABG & & & 41 & & & \\
\hline Nonfunctioning RITAs & & & 3 & & & \\
\hline Patent ITA graft & & & $109(94 \%)$ & 112 & & .54 \\
\hline Predictors for nonfunctional, & occlud & tivariat & analysis according $t$ & ise mult & c regres & \\
\hline Variable & $\boldsymbol{\beta}$ & $\beta$ SE & B & B SE & $t$ & $P$ value \\
\hline Small perfusion area & .045 & .06 & .038 & 0.05 & 0.76 & .45 \\
\hline Small ITA caliber & .21 & .056 & 0.14 & 0.037 & 3.78 & .00018 \\
\hline $\operatorname{ReCA}<1.5 \mathrm{~mm}$ & .15 & .06 & 0.12 & 0.049 & 2.53 & .012 \\
\hline Stenosis of $\operatorname{ReCA}<60 \%$ & .14 & .056 & 0.12 & 0.048 & 2.43 & .016 \\
\hline PL branch & .037 & .049 & 0.019 & 0.025 & 0.75 & .46 \\
\hline Off pump & -.012 & .048 & -0.012 & 0.021 & -0.06 & .73 \\
\hline Diffuse stenosis of ReCA & .13 & .052 & 0.065 & 0.027 & 2.44 & .015 \\
\hline Age $>70$ y & -.003 & .056 & -0.0018 & 0.036 & -0.05 & .96 \\
\hline Diabetes & .065 & .051 & 0.04 & 0.032 & 1.27 & .21 \\
\hline LVEF $<35 \%$ & -.033 & .051 & -0.02 & 0.03 & -0.65 & .52 \\
\hline Female sex & .071 & .049 & 0.041 & 0.029 & 1.43 & .15 \\
\hline Dyslipidemia & -.067 & .049 & -0.044 & 0.033 & -1.36 & .17 \\
\hline
\end{tabular}

$I T A$, Internal thoracic artery; $L A D$, left anterior descending artery; $P L$, posterolateral branch of the circumflex artery; RITA, right internal thoracic artery; $C A B G$, coronary artery bypass grafting; $R e C A$, recipient coronary artery; $L V E F$, left ventricular ejection fraction.

Bilateral in situ ITA grafting to the left coronary system has been recognized as a major determinant of survival. ${ }^{17,21}$ A potential advantage of anastomosing both in situ ITAs to the left coronary system may result from the fact that the coronary bypass flow depends on both ITAs, resulting in less risk of hypoperfusion. Different configurations have been proposed for anastomosing both ITAs to the left coronary system; however, the best strategy has not yet been established. One option is to anastomose the s-RITA to the LAD and the s-LITA to the obtuse marginal branch. A major objection to the retrosternal s-RITA crossover routing is the potential risk of damage during re-sternotomy. ${ }^{23}$ Another possibility is to use the f-RITA, but reduced patency rates for f-RITA have been shown when these grafts are connected proximally to the aorta. ${ }^{1}$ Attachment of the f-RITA to the s-LITA (T or Y graft) may improve paten$\mathrm{cy},{ }^{20}$ but this configuration does not apply the principle of
LV revascularization from 2 different in situ sources. In 1984, Puig and colleagues ${ }^{24}$ reported the s-RITA via the transverse sinus for circumflex artery grafting. This configuration, associated with the s-LITA anastomosed to the LAD, offers a series of advantages: (1) the LAD is revascularized by the s-LITA, which is well accepted as a gold standard technique; (2) the left coronary system is perfused by 2 in situ ITAs; (3) it avoids the difficulties of anastomosing a thin-walled vessel, such as the f-RITA, to a thick-walled vessel, such as the aorta; (4) there are no grafts crossing the midline behind the sternum, and both ITAs are in a safe position, which decreases the risks in case of mediastinal revision or reoperation; (5) it offers the possibility to easily apply the no-touch principle by using different composite graft configurations ${ }^{13-15}$; (6) the caliber and flow of the distal segment of skeletonized ITA is greater compared with pedicled ITA ${ }^{14}$; and (7) fewer anastomoses 
TABLE 6. Transthoracic echo color Doppler data before and after adenosine provocative test at 3 months after surgery in 86 patients undergoing right or Y-T-graft construction with in situ RITA (indexed by corporeal surface: $1.74 \pm 0.5 \mathrm{~m}^{2}$ )

\begin{tabular}{|c|c|c|c|c|}
\hline \multirow[b]{3}{*}{ Variable } & \multicolumn{4}{|c|}{3 mo after surgery } \\
\hline & \multicolumn{2}{|c|}{ At rest } & \multicolumn{2}{|c|}{ After adenosine } \\
\hline & LITA & RITA & LITA & RITA \\
\hline Diameter $_{\mathrm{i}}\left(\mathrm{mm} / \mathrm{m}^{2}\right)$ & $1.41 \pm 0.6$ & $1.56 \pm 0.5$ & $1.65 \pm 0.4$ & $1.9 \pm 0.6$ \\
\hline $\begin{array}{l}\text { Mean velocity } \\
\quad\left(\mathrm{cm} \cdot \mathrm{s}^{-1} \cdot \mathrm{m}^{-2}\right)\end{array}$ & $20 \pm 5$ & $21 \pm 6$ & $40 \pm 7$ & $48 \pm 8$ \\
\hline $\begin{array}{l}\text { Mean flow } \\
\quad\left(\mathrm{mL} \cdot \mathrm{min}^{-1} \cdot \mathrm{m}^{-2}\right)\end{array}$ & $70 \pm 8$ & $104 \pm 15$ & $157 \pm 10$ & $258 \pm 14$ \\
\hline Graft flow reserve & \multicolumn{4}{|c|}{$\begin{array}{l}\text { LITA }=2.24 \pm 0.6 \\
\text { RITA }=2.48 \pm 0.5(P=.003)\end{array}$} \\
\hline
\end{tabular}

LITA, Left internal thoracic artery; RITA, right internal thoracic artery; mean velocity $_{i}$, mean velocity of flow in the ITA indexed by corporeal surface; mean flow $w_{i}$, mean flow in the ITA indexed by corporeal surface.

are required. Other authors have hypothesized that the retroaortic course of the s-RITA might be associated with some disadvantages, such as the inability to control bleeding from retroaortic s-RITA branches, ${ }^{12,25}$ aortic compression of the s-RITA, ${ }^{25}$ and compromised graft patency because of undetected kinks, graft overstretching, and rotation. In our experience, harvesting the RITA according to the skeletonized technique permits a better localization of the side branches, which are carefully clipped. In our series, we found a normal postoperative bleeding rate, and no patient had postoperative bleeding requiring re-exploration, because of RITA side branches. Rankin and colleagues, ${ }^{25}$ in a series of 20 patients who underwent s-RITA via the transverse sinus, reported 2 RITA occlusions and low flow in 3 patients. However, we believe that such disastrous outcomes were probably due to the technique (pedicle), difficulties in RITA harvesting, or small RITA caliber, rather than to the aortic compression that remains possible when larger pedicled ITAs are used. We believe that-with ITA skeletonization, a proportional pleural bed, and, eventually, retrocaval routing - graft kinking, compression, and overstretching during inspiration are almost impossible. In 2 postoperative occluded RITAs in our series, we did not find the kinking phenomenon. When the s-RITA is anastomosed to the circumflex artery, however, once anastomosis is completed, the course of the graft seems to be smooth because of a lack of exposure to tension or excessive motion.

In the report by Ramstrom and colleagues, ${ }^{12}$ the s-RITA through the transverse sinus could reach only the most proximal parts of circumflex system; consequently, the sRITA was predominantly used to revascularize the LAD. Buche and associates ${ }^{11}$ reported that patients who receive the s-RITA via the transverse sinus represent only $52 \%$ of the patients who undergo circumflex artery grafting. They did not, however, mention the exact percentage of s-RITAs that could not be used because of anatomic limitations in the remaining $48 \%$ of patients. Tatoulis and associates, ${ }^{3}$ who reported on 1454 f-RITAs (from which 552 were anastomosed to the first obtuse marginal branch and 166 to the second obtuse marginal branch), confirmed the opinion that anastomosing this graft to the obtuse marginal arteries is the best alternative; however, the authors believe that the sRITA length is not adequate for grafting to these vessels. In our experience, we did not find s-RITA grafting to the obtuse marginal difficult. This may result from differences in our surgical strategy or the RITA harvesting technique. In our practice, to use the distal RITA segment with an acceptable caliber, care is taken to obtain the maximum length by harvesting the RITA near its origin from the subclavian artery and to obtain the shortest route by creating the ITA bed and by routing through the transverse sinus. We have never changed the target vessel because of length inadequacy, and the success rate for anastomosing the preoperatively targeted vessel was 100\%, even though a considerable number of the target coronary arteries were distal branches of the circumflex artery. This confirms that skeletonized s-RITA via the transverse sinus can reach most branches of the circumflex system, even the most distal ones, as the posterolateral arteries. Routing of the s-RITA behind the superior caval vein and further into the transverse sinus allows additional length without opening the pleura; this facilitates lateral coronary artery grafting via a less circuitous and more protected route. ${ }^{26}$

Another point of controversy is the use of the distal RITA portion. We routinely used the distal portion of the RITA. Dietl and associates ${ }^{27}$ reported an increased rate of RITA graft failure when the distal RITA was used to bypass the posterior descending artery, attributing this problem to spasm of the distal RITA's end. Morin and associates ${ }^{28}$ reported a low patency rate for the 2 terminal branches of the ITAs. The 2 branches of the ITA are muscular arteries, with occasional elastic lamellae, although the midportion of the main ITA is more elastic. Morin and colleagues ${ }^{29}$ reported increased contractility of the ITA toward the distal end; however, the authors mentioned that there are not enough data to show that extensive use of the distal section of the ITA increases the likelihood of spasm or graft failure. Our present study showed that the use of the skeletonized s-RITA distal segment did not increase the graft failure rate, at least in the early period, so long as an ITA with adequate flow and caliber was used. Probably the high graft failure rate of bypass with the terminal branches is not due to a greater likelihood of contraction or spasm but to technical difficulties, such as small diameter or increased graft tension. ${ }^{9}$ 


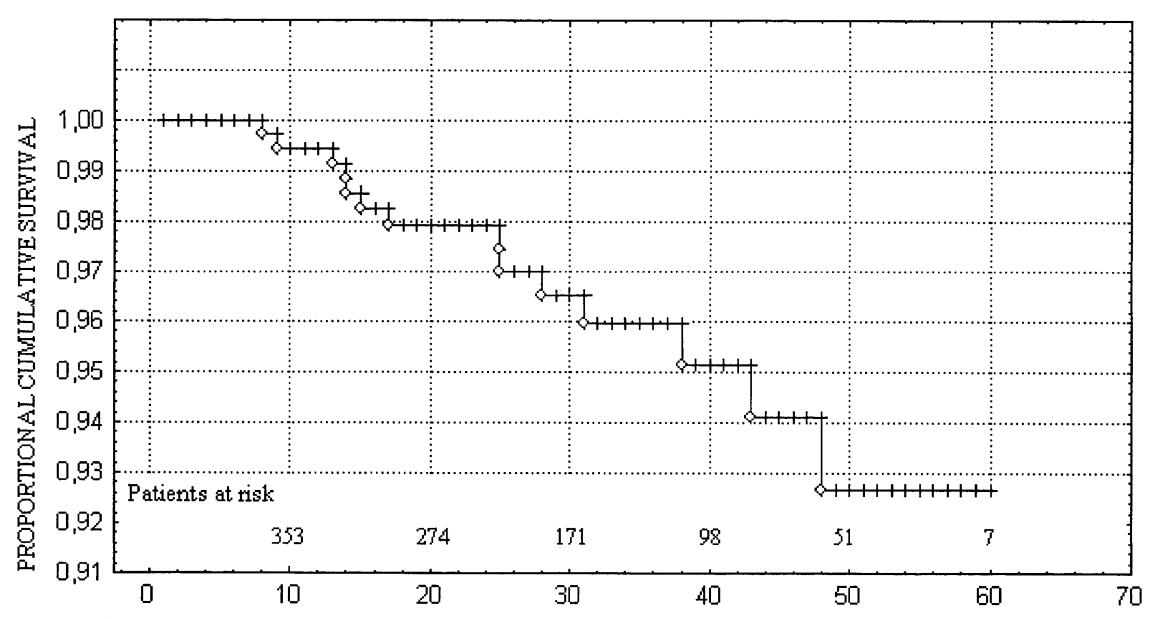

A

FOLLOW-UP TIME (months)



B

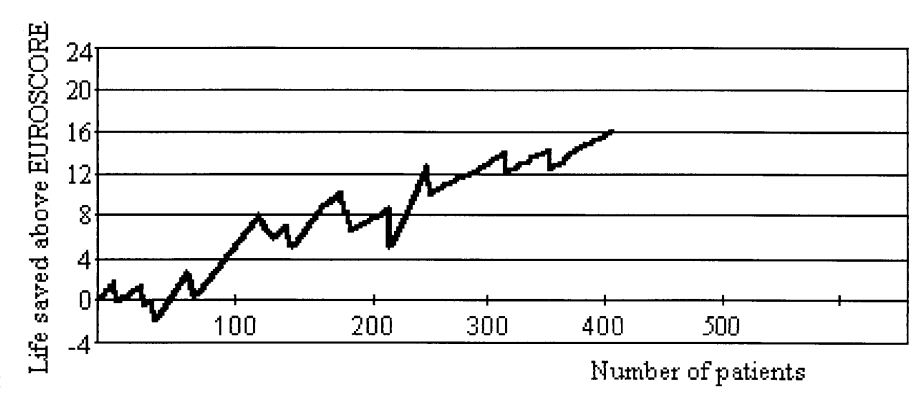

Figure 1. Actuarial survival curves at follow-up. A, Actuarial cumulative survival. B, Actuarial event-free cumulative survival. C, Cumulative risk-adjusted mortality for the study group.

The early postoperative outcomes were excellent, taking into consideration that almost $21 \%$ of patients had impaired LV function and almost $14.4 \%$ of patients underwent combined operations. The predictors for poor postoperative survival were similar to those in series of patients undergoing conventional CABG. Creating the shortest route, the sRITA might be anastomosed with excellent results to the target coronary artery, even in women, individuals with smaller body size, and elderly patients. The authors' opinions are different regarding the use of the s-RITA via the transverse sinus in women or patients with smaller body size. Some studies showed that the s-RITA length was not adequate for being grafted to the obtuse marginal branch in this subgroup. ${ }^{29}$ Ura and colleagues, ${ }^{9}$ in a series of 393 

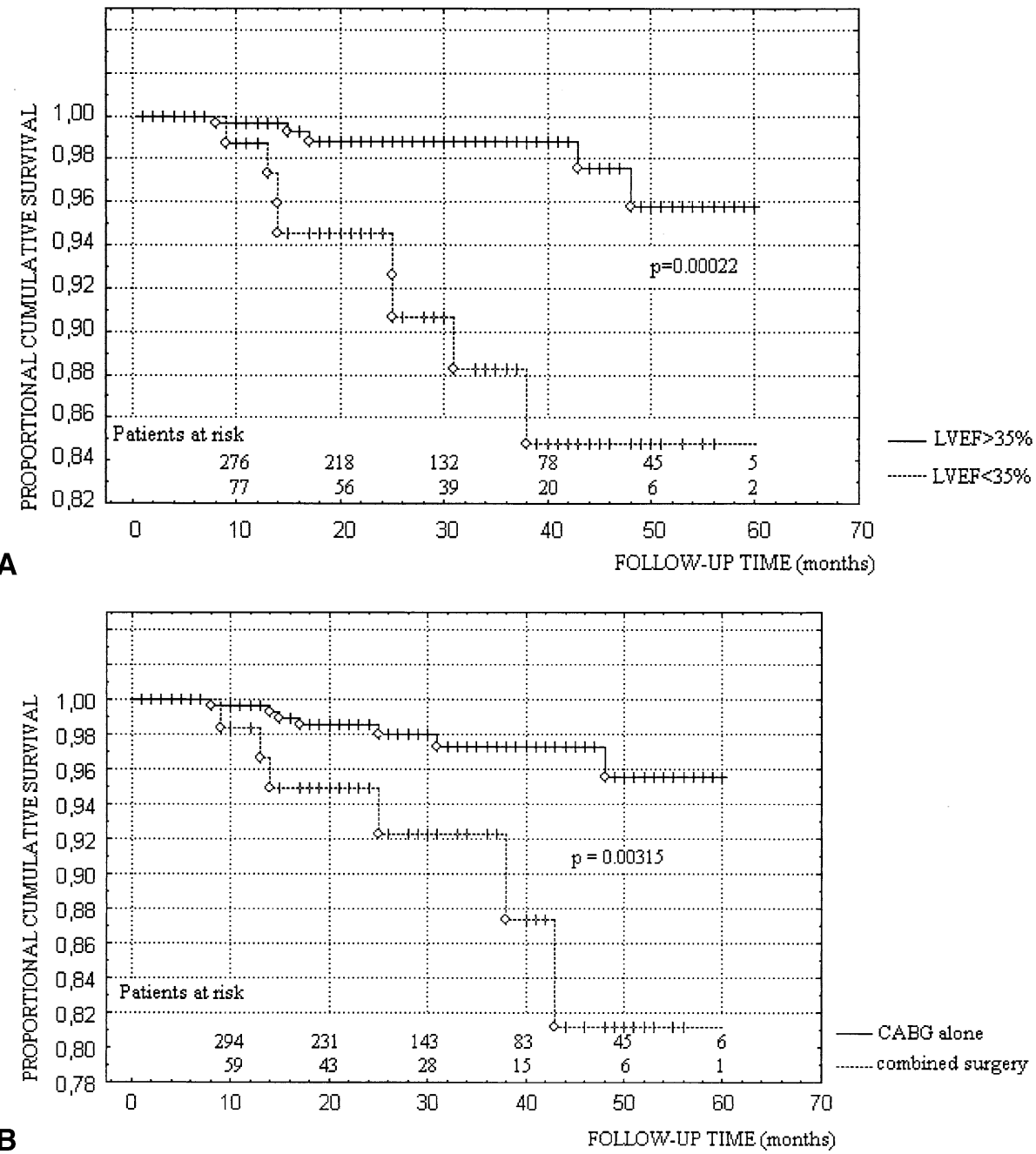

B

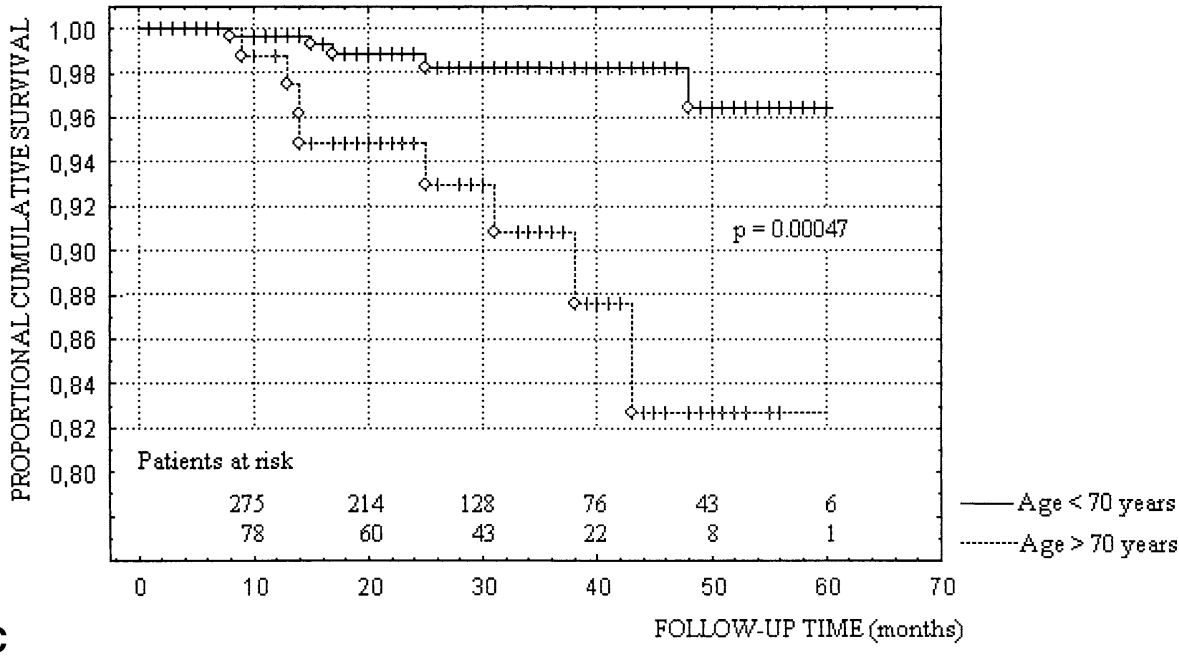

Figure 2. Actuarial survival between patients as follows: A, Patients with an LVEF greater than $35 \%$ and those with an LVEF less than 35\%; B, patients undergoing CABG alone or in association with other surgical procedures; $C$, patients older than 70 years versus younger than 70 years. 

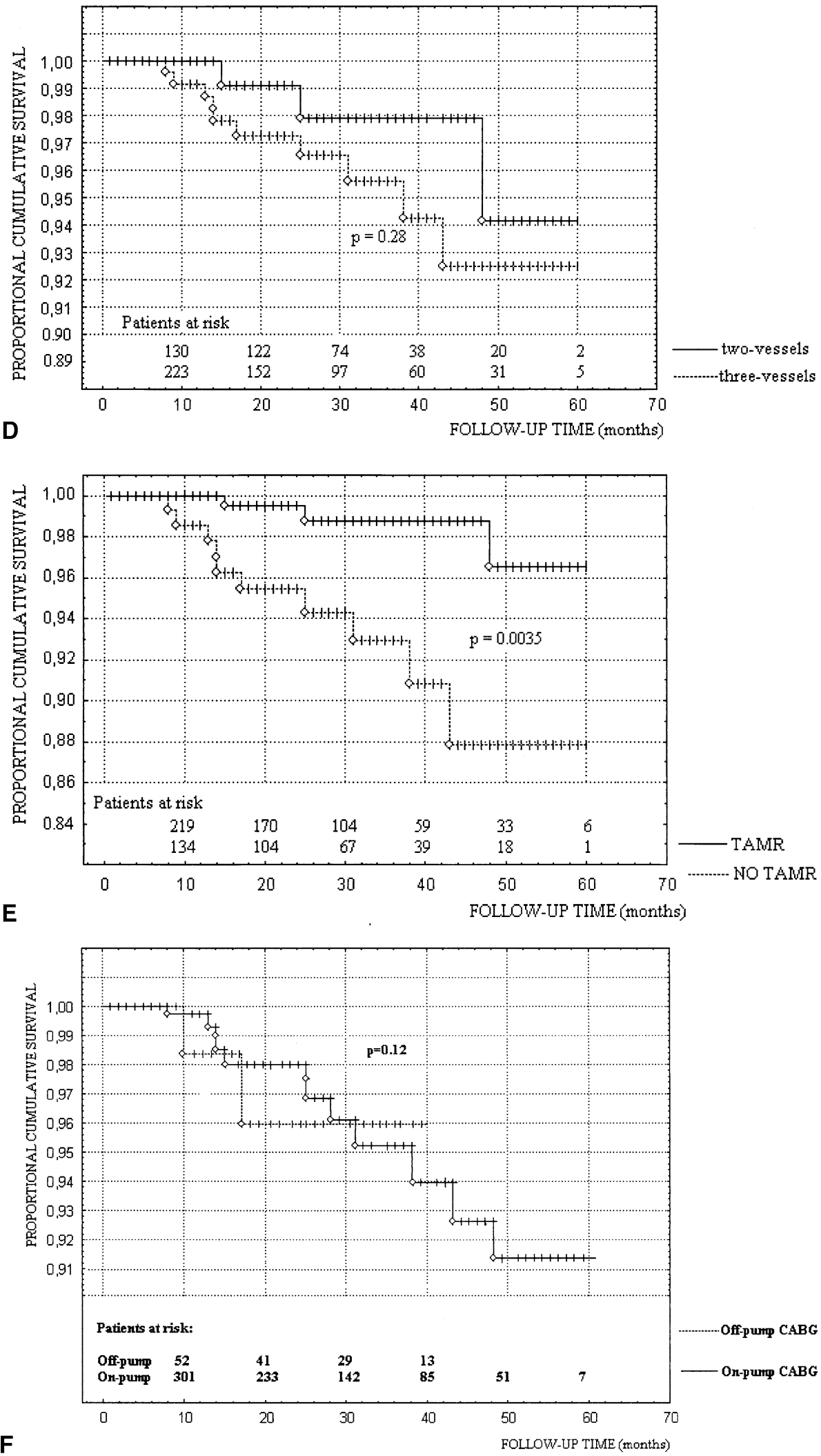

Figure 2. Cont'd. Actuarial survival between patients as follows: D, Patients with 3-vessel disease versus 2-vessel disease; $E$, patients with TAMR versus non-TAMR; and F, patients undergoing on-pump versus off-pump CABG. 
s-RITAs harvested according to the pedunculated technique, did not find difficulties with anastomosing this graft via the transverse sinus to the circumflex system, even in patients with smaller body size. The incidence of deep sternal wound infection in our series was low $(1.1 \%)$, indicating that the use of both ITAs and the described harvesting technique does not increase the postoperative incidence of deep sternal wound infection and other complications, as previously reported, ${ }^{1,17,21-29}$ independently of the presence of diabetes or chronic obstructive disease. Despite a short follow-up, patients who underwent TAMR had a better event-free survival. This is probably because TAMR was preferred in young patients with good LV function. Initially in our experience, in patients older than 70 years, we successfully used both ITAs when a heavily calcified aorta, varicose saphenous veins, or saphenectomy was present. Later on, we routinely used both ITAs in this age group, believing that this strategy reduced the cardiopulmonary bypass time (fewer anastomoses to be constructed) and minor aortic manipulation. Although age was an independent risk factor for poor overall event-free survival, we believe that this was due to the associated pathologic conditions in this subgroup and also to a series of intrinsic variables, such as atherosclerosis progression, calcification of the artery walls, previous myocardial infarction, and combined operations (valve replacement). In 116 patients who underwent postoperative coronary arteriography, 11 ITAs were nonfunctional. Ura and colleagues, ${ }^{9}$ in a series of 381 patients from 393 patients who underwent s-RITA grafting via the transverse sinus, found a $97.2 \%$ and $94.1 \%$ patency rate of the s-LITA and s-RITA, respectively. Ueyama and colleagues ${ }^{8}$ found $97.4 \%$ of s-RITAs grafted via the transverse sinus during the early postoperative course. Buche and colleagues ${ }^{11}$ found 73 patent s-RITAs out of 74 patients who underwent angiography at mean of 13.2 months after operation, from a series of 256 patients who underwent s-RITA grafting through the transverse sinus. It is interesting to note that in our series, age older than 70 years was not identified as an independent risk factor for nonfunctional ITAs. Such a finding shows that the shorter event-free survival in the subgroup of patients older than 70 years is not related to the technique used, consisting in bilateral ITAs for LV revascularization. The predictors for nonfunctional ITAs were small recipient coronary artery caliber, moderate stenosis of the recipient coronary artery of less than $60 \%$, and diffuse stenotic lesions of the recipient coronary artery. A possible hypothesis for nonfunctional ITAs in such a condition is the mismatch between the graft and recipient coronary artery sizes. Other factors that may induce such a phenomenon might be "medial necrosis and fibrosis secondary to the ischemic insult of mobilization."10 To accomplish a full evaluation of the constructed right $Y$ or T graft with in situ RITA, ${ }^{13-15}$ we studied the ITA's dy- namic flow by using transthoracic echo color Doppler contrast-enhanced imaging before and after the adenosine provocative test. The graft flow reserve measured at the RITA stem was higher than at the LITA because of higher runoff of the RITA related to the composite graft. The increased RITA flow reflects the greater supported myocardial area. ${ }^{30}$

This study had several limitations. (1) This was not a randomized study. (2) The target vessels were determined mainly by the perfusion area of the recipient artery and were not selected randomly. (3) Not all patients underwent postoperative angiography, mainly because of limited financial resources or because they did not agree to have the angiogram. This study satisfactorily demonstrates that the skeletonized s-RITA via the transverse sinus and, eventually, retrocavally can reach most branches of the circumflex system with an excellent patency rate, offering the possibility of various configuration constructions, making possible TAMR with a minimum number of arterial conduits. The presence of diabetes, severe obesity, small body size, chronic obstructive pulmonary disease, female sex, older age, or LV dysfunction seems not to represent critical contraindications for such a strategy.

\section{References}

1. Fiore AC, Naunheim KS, Dean P, Kaiser GC, Pennington G, Willman $\mathrm{VL}$, et al. Results of internal thoracic artery grafting over 15 years: single versus double grafts. Ann Thorac Surg. 1990;49:202-9.

2. Pick AW, Orszulak TA, Anderson B, Schaff HV. Single versus bilateral internal mammary artery grafts: 10-year outcome analysis. Ann Thorac Surg. 1997;64:599-605.

3. Tatoulis J, Buxton BF, Fuller JA. Results of 1454 free right internal thoracic artery-to-coronary artery grafts. Ann Thorac Surg. 1997;64: 1263-9.

4. Lev-Ran O, Pevni D, Matsa M, Paz Y, Kramer A, Mohr R. Arterial myocardial revascularization with in situ crossover right internal thoracic artery to left anterior descending artery. Ann Thorac Surg. 2001;72:798-803.

5. Sofer D, Gurevitch J, Shapira I, Paz Y, Matsa M, Kramer A, et al. Sternal wound infection in patients after coronary artery bypass grafting using bilateral skeletonized internal mammary arteries. Ann Surg. 1999;229:585-90.

6. Salm TJV, Chowdhary S, Okike ON, Pezzella AT, Pasque MK. Internal mammary artery grafts, the shortest route to the coronary arteries. Ann Thorac Surg. 1989;47:421-7.

7. Buxton BF, Ruengsakulrach P, Fuller J, Rosalion A, Reid CM, Tatoulis $\mathrm{J}$. The right internal thoracic artery graft-benefits of grafting the left coronary system and native vessels with a high grade stenosis. Eur J Cardiothorac Surg. 2000;18:255-61.

8. Ueyama K, Sakata R, Umebayashi Y, Nakayama Y, Arakaki K, Ura M. In situ right internal thoracic artery graft via transverse sinus for revascularization of posterolateral wall: early results in 116 cases. J Thorac Cardiovasc Surg. 1996;112:731-6.

9. Ura M, Sakata R, Nakayama Y, Arai Y, Oshima S, Noda K. Analysis by early angiography of right internal thoracic artery grafting via the transverse sinus: predictors of graft failure. Circulation. 2000;101: 640-6.

10. Ura M, Sakata R, Nakayama Y, Arai Y, Oshima S, Noda K, et al. Technical aspects and outcome of in situ right internal thoracic artery grafting to the major branches of the circumflex artery via the transverse sinus. Ann Thorac Surg. 2001;71:1485-90.

11. Buche M, Schroeder E, Chenu P, Gurne O, Marchandise B, Pompilio $\mathrm{G}$, et al. Revascularization of the circumflex artery with the pedicled 
right internal thoracic artery: clinical functional and angiographic midterm results. J Thorac Cardiovasc Surg. 1995;110:1338-43.

12. Ramstrom J, Lund O, Cadavid E, Oxelbark S, Thuren JB, Henze AC. Right internal mammary artery for myocardial revascularization: early results and indications. Ann Thorac Surg. 1993;55:1485-92.

13. Bonacchi M, Prifti E, Giunti G, Salica A. Right Y-graft, a new surgical technique using mammary arteries for total myocardial revascularization. Ann Thorac Surg. 2000;70:820-3.

14. Prifti E, Bonacchi M, Frati G, Proietti P, Giunti G, Leacche M, et al. Lambda graft with the radial artery or free left internal mammary artery anastomosed to the right internal mammary artery: flow dynamics. Ann Thorac Surg. 2001;72:1275-81.

15. Bonacchi M, Prifti E, Frati G, Leacche M, Salica A, Giunti G, et al. Total arterial myocardial revascularization using internal mammary and/or radial artery conduits according the new composite graft technique. J Card Surg. 1999;14:408-16.

16. Austen WG, Edwards JE, Frye RL, Gensini GG, Gott VL, Griffith LS, et al. A reporting system on patients evaluated for coronary artery disease. Report of the Ad Hoc Committee for Grading of Coronary Artery Disease, Council on Cardiovascular Surgery, American Heart Association. Circulation. 1975;51(suppl 4):5-40.

17. Buxton BF, Komeda M, Fuller JA, Gordon I. Bilateral internal thoracic artery grafting may improve outcome of coronary artery surgery. Circulation. 1998;98:11-6.

18. Tector AJ, Kress DC, Downey FX, Schmahl TM. Complete revascularization with internal thoracic artery grafts. Semin Thorac Cardiovasc Surg. 1996;8:29-41.

19. Calafiore AM, Vitolla G, Iaco AL, Fino C, Di Giammarco G, Marchesani $\mathrm{F}$, et al. Bilateral internal mammary artery grafting: midterm results of pedicled versus skeletonized conduits. Ann Thorac Surg. 1999;67:1637-42.

20. Calafiore AM, Contini M, Vitolla G, Di Mauro M, Mazzei V, Teodori $\mathrm{G}$, et al. Bilateral internal thoracic artery grafting: long-term clinical and angiographic results of in situ versus Y grafts. $J$ Thorac Cardiovasc Surg. 2000;120:990-6.
21. Schmidt SE, Jones JW, Thornby JI, Miller CC III, Beall AC Jr. Improved survival with multiple left-sided bilateral internal thoracic artery grafts. Ann Thorac Surg. 1997;64:9-15.

22. Gurevitch J, Paz Y, Shapira I, Matsa M, Kramer A, Pevni D, et al. Routine use of bilateral skeletonized internal mammary arteries for myocardial revascularization. Ann Thorac Surg. 1999;68:406-12.

23. Joyce FS, McCarthy PM, Taylor PC, Cosgrove DM III, Lytle BW. Cardiac reoperation in patients with bilateral internal thoracic artery grafts. Ann Thorac Surg. 1994;58:80-5.

24. Puig LB, Franca Neto L, Rati M, Ramires JA, da Luz PL, Pileggi F, et al. A technique of anastomosis of the right internal thoracic mammary artery to the circumflex artery and its branches. Ann Thorac Surg. 1984;38:533-4.

25. Rankin JS, Newman GE, Bashore TM, Muhlbaier LH, Tyson GS Jr, Ferguson TB Jr, et al. Clinical and angiographic assessment of complex mammary artery bypass grafting. J Thorac Cardiovasc Surg. $1986 ; 92: 832-46$

26. Pliam MB, Zapolanski A. Retrocaval routing of the right internal thoracic artery. Ann Thorac Surg. 1993;56:181-2.

27. Dietl CA, Benoit CH, Gilbert CL, Woods EL, Pharr WF, Berkheimer $\mathrm{MD}$, et al. Which is the graft of choice for the right coronary and posterior descending arteries? Comparison of the right internal mammary artery and the right gastroepiploic artery. Circulation. 1995; 92(suppl 2):92-7.

28. Morin JE, Hedderich G, Poirier NL, Sampalis J, Symes JF. Coronary artery bypass using internal mammary artery branches. Ann Thorac Surg. 1992;54:911-4.

29. He GW, Ryan WH, Acuff TE, Yang CQ, Mack MJ. Greater contractility of internal mammary artery bifurcation: possible cause of low patency rates. Ann Thorac Surg. 1994;58:529-32.

30. Wendler O, Hennen B, Markwirth T, Konig J, Tscholl D, Huang Q, et al. $T$ grafts with the right internal thoracic artery to left internal thoracic artery versus the left internal thoracic artery and radial artery: flow dynamics in the internal thoracic artery main stem. $J$ Thorac Cardiovasc Surg. 1999;118:841-8. 